\title{
sensors
}

ISSN 1424-8220

(C) 2005 by MDPI

http://www.mdpi.org/sensors

\section{DNA Biosensor for Rapid Detection of Genotoxic Compounds in Soil Samples}

\section{Graziana Bagni $^{1, *}$, Silvia Hernandez ${ }^{1,2}$, Marco Mascini ${ }^{1, *}$, Elena Sturchio ${ }^{3}$, Priscilla Boccia ${ }^{3}$ and Simona Marconi ${ }^{4}$}

${ }^{1}$ Department of Chemistry, University of Florence, Via della Lastruccia 3, 50019 Sesto Fiorentino (Firenze), Italy.

${ }^{2}$ Department of Chemistry, National University of Littoral, University Campus, 3000 Santa Fe, Argentina

${ }^{3}$ Department Industrial Installations and Interaction with the Environment (DIPIA), National Authority for Health and Safety at Work (ISPESL), Via Urbana 167, 00184 Rome, Italy

${ }^{4}$ National Institute of Soil Defence (ISSDS), Via Casette 1, 02100 Rieti, Italy

*Author to whom correspondence should be addressed: phone +390554573283 ; fax +390554573384 ;

e-mail: marco.mascini@unifi.it

Received: 25 February / Accepted: 30 March 2005 / Published: 14 November 2005

\begin{abstract}
An electrochemical DNA-based biosensor is proposed as a fast and easy screening method for the detection of genotoxic compounds in soil samples. The biosensor was assembled by immobilising double stranded Calf thymus DNA on screen-printed electrodes. The interactions between DNA and environmental pollutants can cause variations of the electrochemical proprieties of DNA when they cause a DNA damage. Preliminary studies were performed using benzene, naphthalene and anthracene derivatives as model compounds. The effect of these compounds on the surface-confined DNA was found to be linearly related to their concentration in solution. On the other hand, the objective was to optimise the ultrasonic extraction conditions of these compounds from artificially spiked soil samples. Then, the applicability of such a biosensor was evaluated by analysing soil samples from an Italian region with ecological risk (ACNA of Cengio, SV). DNA biosensor for qualitative analysis of soil presented a good correlation with a semiquantitative method for aromatic ring systems determination as fixed wavelength fluorescence and interestingly, according results were found also with other bioassays.
\end{abstract}


This kind of biosensors represent a new, easy and fast way of analysis of polluted sites, therefore they can be used as early warnings devices in areas with ecological risk as in situ measurement.

Keywords: DNA damage, electrochemical DNA biosensors, genotoxicity, soil contamination.

\section{Introduction}

The soil plays a central role within ecosystems and fulfils a multitude of functions (as a habitat and with regulatory and production functions). On reaching soils, pollutants can adversely affect these functions, thus they can move to other media and cause damage to other components of the ecosystem.

Soil contamination comprises either solid or liquid hazardous substances becoming mixed with the naturally occurring soil. Usually, contaminants in the soil are physically or chemically attached to soil particles, or if they are not attached, trapped in the small spaces between soil particles. Soil contamination results when hazardous substances are either spilled or buried directly in the soil or migrate to the soil from a spill that has occurred elsewhere. Another source of soil contamination could become from water flowing nearby soils containing hazardous substances.

Contaminants in the soil can adversely impact the health of animals and humans when they ingest, inhale, or touch contaminated soil, or when they eat plants or animals that have themselves been affected by soil contamination. Animals ingest and come into contact with contaminants when they burrow in contaminated soil. Humans ingest and come into contact with contaminants when they play in contaminated soil or dig in the soil as part of their work. Certain contaminants, when they contact our skin, are absorbed into our bodies. When contaminants are attached to small surface soil particles they can become airborne as dust and can be inhaled.

Plants can be damaged when they attempt to grow in contaminated soil and take up the contamination through their roots. It has been studied that soils exposed to industrial effluents, areas next to smelters and mine spoils have the greatest accumulations of arsenic, and plants and soil invertebrates living in arsenic contaminated soil, have been shown to accumulate arsenic [1].

The exposure of an organism to a carcinogen or other ecotoxic compound in soil is not related to the total concentration of that substance in soil but rather to the amount that is actually available (bioavailability) [2]. Most chemical extraction methods reported in literature were studied in terms of their ability to recover all the contaminants (PAH, pesticides, etc) from a soil matrix [3, 4]. In this work we propose the use of a fast and simple analytical extraction method to mimic the bioaccessibility determined by a contaminated Italian ex industrial area, the Associated National Chemical Companies (ACNA) (Cengio, SV, Italy) site. This is a closed organic chemical industrial factory active since 1882 with the production of explosives (nytroglicerin, dynamite and trinitrotoluene), paints, nitric and sulphuric acids, phenols and amines, with serious levels of 
contamination of soil and surface waters, where a remediation and bonification plan started in 1999 . The serious environmental contamination of this area determined its inclusion in the list of national priorities for environmental reclamation.

The extraction was followed by a screening method for the rapid detection of genotoxic compounds in soil samples as electrochemical DNA-based biosensor [5-7]. Preliminary studies were performed using benzene, naphthalene and anthracene derivatives standard solutions as more representative organic compounds present in the site [8-10]. The effect of these compounds on the surface-confined DNA was found to be linearly related to their concentration in solution. Then, the applicability of such biosensor was evaluated by analysing soil samples from the site.

\section{Experimental}

\subsection{Materials}

Milli-Q grade water (18 $\mathrm{M} \Omega$ ) was used for the preparation of all solutions (Milli-Q water purification system, Millipore, UK). Inorganic salts for buffers preparation and ethanol were obtained from Merck (Milan, Italy). Calf thymus double-stranded DNA type XV was purchased from Sigma (Milan, Italy). Using sterile pipettes, aliquots containing $1000 \mu \mathrm{g} / \mathrm{mL}$ of DNA in milli-Q water were prepared and stored in freezer $\left(-20^{\circ} \mathrm{C}\right)$. Acetate buffer concentration was $0.25 \mathrm{M}(\mathrm{pH}=4.75)$ with 10 $\mathrm{mM} \mathrm{KCl}$. The effect of three benzene, two naphthalene and four anthracene derivatives were analysed in this work with DNA biosensor because widely present in the ACNA site [8-10]: sodium benzenesulfonate, 4-chloroaniline, 3,4-dichloroaniline, 2-naphtylamine, sodium 2naphthalenesulfonate, sodium anthraquinone 2-sulfonate monohydrate, 2-anthracencarboxylic acid, 1,2-diaminoanthraquinone and 2-anthramine (all from Sigma-Aldrich (Milan, Italy)).

\subsection{Apparatus}

Electrochemical measurements were performed with a PalmSens (Palm Instruments BV, Hoten, Netherlands) interfaced to a Compaq iPAQ Pocket PC with a PalmScan 1.3 software package (Palm Instruments BV, Hoten, Netherlands) and screen-printed electrodes (SPE). The electrodes were screenprinted in house using a DEK 248 screen-printing machine (DEK, Weymouth, UK). The cell consisted of a graphite working electrode with a diameter of $3 \mathrm{~mm}$, a graphite counter electrode and a silver pseudo-reference electrode. Each electrode was disposable and used for one measurement only. Details on SPE are reported in [7].

An autovortex mixer SA2 (Stuart Scientific, Surrey, UK) and filters $0.45 \mu \mathrm{m}$ (Schleicher \& Schuell Italia, Legnano (MI), Italy) were used respectively to homogenise the solvent-soil suspensions and to filter the extracts. In order to check the effectiveness of the extraction the extracts were analysed through UV spectroscopy with a Unicam 8625 UV-VIS spectrometer (Cambridge, UK) with these parameters: $\lambda_{\text {range }}=195-380 \mathrm{~nm} ; \lambda_{\text {step }}=5 \mathrm{~nm} ; \lambda_{\text {absorbance }}=255 \mathrm{~nm}$. 
The ultrasound bath was a Branson 3200 sonicated bath (Midland, Canada). The ultrasound probe was a model VC100 Vibra Cell from Sonics and Materials (Danbury, USA) with the following characteristics: power supply 100 Watts; frequency $20 \mathrm{kHz}$; converter: piezoelectric lead zirconate titanate crystals (PZT), diameter $32 \mathrm{~mm}$ and length $46 \mathrm{~mm}$; Ti probe tip ( $\varnothing=5 \mathrm{~mm}$ ) placed at 1/3 of the suspension height.

Fluorescence measurements were performed in a quartz cuvette on a Jasco FP 750 luminescence spectrometer (Essex, UK). Slit widths were set at $10 \mathrm{~nm}$ for both excitation and emission wavelengths, sensitivity medium and response 1 sec. The signal level in solvent blank was subtracted and the fluorescence level was expressed as relative fluorescence intensity.

\subsection{Biosensor procedure}

The guanine oxidation peak was used as the transduction signal in systems detecting DNA interacting agents. As a result of interaction of double stranded calf thymus DNA with a pollutant agent a decrease of guanine peak (measured by square-wave voltammetry) was detected. DNA modification was estimated by the percentage change in the guanine peak height (Signal\%), which was taken as the ratio of the guanine peak height after the interaction with a sample $\left(\mathrm{S}_{\mathrm{s}}\right)$, to the guanine peak height in buffer solution $\left(\mathrm{S}_{\mathrm{b}}\right)$ : Signal \% $=\left(\mathrm{S}_{\mathrm{s}} / \mathrm{S}_{\mathrm{b}}\right) * 100$.

The experiments were performed at room temperature, according to the following sequence:

1. Electrode pre-treatment: the potential applied was $+1.6 \mathrm{~V}$ for $120 \mathrm{~s}$ and $+1.8 \mathrm{~V}$ for $60 \mathrm{~s}$; electrodes were in $5 \mathrm{~mL}$ of $0.25 \mathrm{M}$ acetate buffer containing $10 \mathrm{mM} \mathrm{KCl}(\mathrm{pH}=4.75)$ under stirred conditions.

2. DNA immobilisation: Electrodes were immersed in 50 ppm Calf thymus dsDNA in 0.25 $\mathrm{M}$ acetate buffer with $10 \mathrm{mM} \mathrm{KCl}$ and a potential of $+0.5 \mathrm{~V}$ was applied for $5 \mathrm{~min}$ under stirred conditions.

3. Blank or sample interaction: the incubation step was performed by simply placing 10 $\mu \mathrm{L}$ of the sample solutions onto the working electrode surface for $2 \mathrm{~min}$. Soil samples had been extracted and filtered before the analysis.

4. Measurement: a square wave voltammetric scan was carried out to evaluate the oxidation of guanine residues on the electrode surface. The height of the guanine peak (at $+0.95 \mathrm{~V}$ vs. Ag screen-printed pseudo-reference electrode) was measured. The scan was made in $0.25 \mathrm{M}$ acetate buffer, containing $10 \mathrm{mM} \mathrm{KCl}$ using the following parameters: scan from $+0.2 \mathrm{~V}$ to +1.35 $\mathrm{V}, \mathrm{E}_{\text {step }}=15 \mathrm{mV}, \mathrm{E}_{\text {amplitude }}=40 \mathrm{mV}$, Frequency $=200 \mathrm{~Hz}$.

\subsection{Soil samples}

Reference soil was collected in a reference site in Florence (Italy). Soil samples were collected from the soil layers $\left(0-30 \mathrm{~cm}\right.$ ) in a specific ACNA site (Cengio, SV, Italy) (hill $\mathrm{n}^{\circ} 5$ ) on March 2003 and in major depth on January 2004. The soil was dried 24 h at r.t. [3], pulverised in a mortar, homogenise 
passing trough a metal sieve $(\varnothing=0.8 \mathrm{~mm})$ and stored at r.t. until extraction. The extraction was performed on $0.5 \mathrm{~g}$ of soil, according to the optimised procedure obtained with artificially polluted samples with an ultrasound probe for $2 \mathrm{~min}$ in $10 \mathrm{~mL}$ of $50 \mathrm{mM}$ phosphate buffer $\mathrm{pH} 3.0$ or 7.5, followed by an equilibration of 3 min at r.t. and a filtration.

\subsection{Statistical analysis}

A one-way analysis of variance (ANOVA) was used to compare between the different sample groups. Dunnett's test was used to determine the significance of differences between the sample groups and the control (blank assay) group. When the ANOVA indicated that significant differences existed, Fisher's "least-significant difference" (LSD) multiple comparison test was then used. Statistical analysis were performed with Excel software. Parametric tests were preceded by tests for normal distribution per site, and for homogeneity of variance between sites. A significance level of $\mathrm{P}<$ 0.05 was applied in all statistical tests.

\section{Results and discussion}

\subsection{Analysis of standard solution with DNA biosensor}

The effect of three benzene, two naphthalene and four anthracene derivatives were analysed in this work with DNA biosensor because widely present in the ACNA site. The molecular structures of the compounds analysed are reported in Figure 1. The voltammetric behaviour of the biosensor with and without $1.0 \mu \mathrm{M}$ 2-anthramine standard solution is shown in Figure 2. Different concentrations for each compound were analysed and the inhibition of the guanine oxidation peak increased with analyte concentration (Table 1 and Figure 3).

The results demonstrated that the compounds presented different genotoxic effect. Generally, the effect was higher with increased ring number of the molecule, and also the type of the group had a relevance. For example, the amino group was more toxic than a sulfonate one at the same molecular concentration. The results showed the highest toxic effect for molecules with three rings. In fact the naphthalene and anthracene derivatives analysed are DNA intercalating agents [5, 6, 11], while the benzene derivatives are not double helix intercalant but only a weak DNA interactive (i.e. as reported in [11], 4-chloroaniline is described as non genotoxic and its cytotoxicity, measured as cell viability assay, is relatively low compared with other chemicals).

This work demonstrated that naphthalen-sulfonate derivatives with two and three aromatic rings and aromatic amines with two and three rings gave a positive result with the biosensor in a concentration range of micro and submicro-molar. The $\mathrm{EC}_{50}$ value was $2.0 \mu \mathrm{mol} / \mathrm{L}$ for 2anthracenecarboxylic acid and 1,2-diamineanthraquinone and $1.0 \mu \mathrm{mol} / \mathrm{L}$ for 2-anthramine. 
Sensors 2005, 5

Derivative of

Benzene

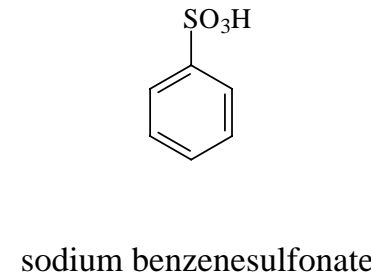

(BS)

Naphthalene<smiles>Nc1ccc2ccccc2c1</smiles>

2-naphtylamine

(NA)

Anthracene<smiles>O=C1c2ccccc2C(=O)c2c1cccc2S(=O)(=O)O</smiles>

sodium anthraquinone 2-sulfonate monohydrate

(AQS)<smiles>O=C(O)c1ccc2cc3ccccc3cc2c1</smiles>

2-anthracencarboxilic acid

(AAC)<smiles>Nc1ccc(Cl)cc1</smiles>

4-chloroaniline (CA)<smiles>O=S(=O)(O)c1ccc2ccccc2c1</smiles>

sodium 2-naphtalenesulfonate (NS)<smiles>Nc1ccc2c(c1N)C(=O)c1ccccc1C2=O</smiles>

1,2-diamineanthraquinone

(DAA)<smiles>Nc1ccc2cc3ccccc3cc2c1</smiles>

(AT)

Figure 1. Sketch of the molecules analysed. 


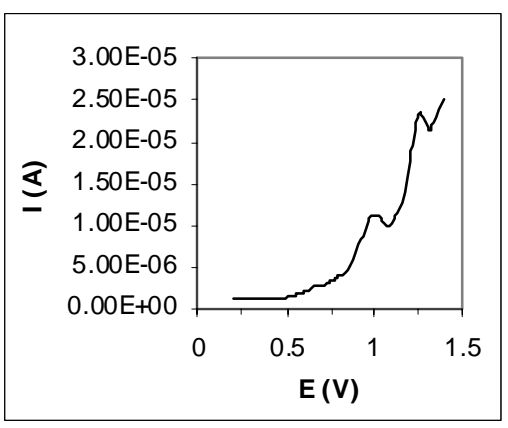

(a)

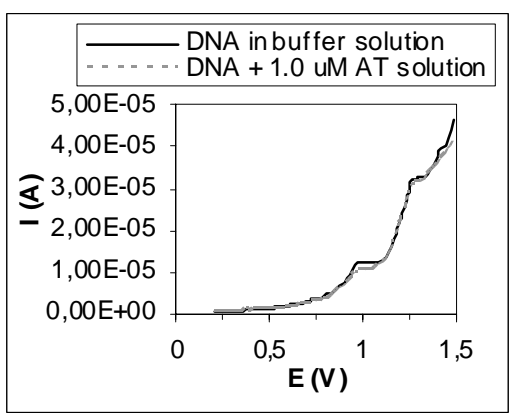

(b)

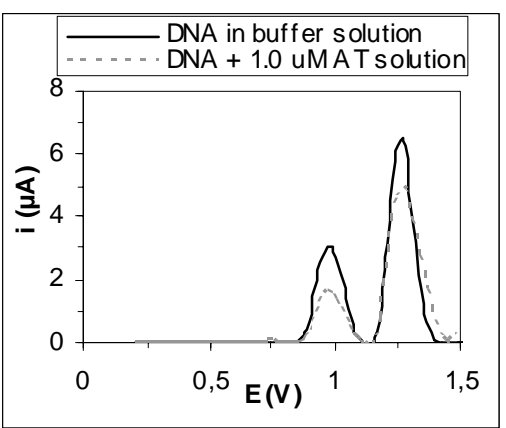

(c)

Figure 2. Redox behavior of guanine (+1.0 V vs. Ag - SPE) and adenine (+1.25 V vs. Ag - SPE) bases after a square wave voltammetric scan carried out with graphite screen printed working electrode. It can be noted the normal signal (a), the decrease of the DNA peaks after the interaction with a $1.0 \mu \mathrm{M}$ 2-anthramine standard solution (b) and the signals after a baseline correction (c). Electrode pre-treatment: $+1.6 \mathrm{~V}$ (vs. Ag - SPE) for $120 \mathrm{~s}$ and $+1.8 \mathrm{~V}$ (vs. Ag SPE) for $60 \mathrm{~s}$ in $5 \mathrm{~mL}$ of $0.25 \mathrm{M}$ acetate buffer containing $10 \mathrm{mM} \mathrm{KCl} \mathrm{(pH} \mathrm{=} \mathrm{4.75)} \mathrm{under} \mathrm{stirred} \mathrm{conditions;} \mathrm{DNA}$ immobilisation: 50 ppm Calf thymus dsDNA (in $0.25 \mathrm{M}$ acetate buffer with $10 \mathrm{mM} \mathrm{KCl}$ ) applying a potential of $+0.5 \mathrm{~V}$ (vs. Ag - SPE) for 5 min under stirred conditions; blank or sample interaction: $10 \mu \mathrm{L}$ of the sample solutions onto the working electrode surface for $2 \mathrm{~min}$; final measurement: square wave voltammetric scan in $0.25 \mathrm{M}$ acetate buffer containing $10 \mathrm{mM} \mathrm{KCl}$ from $+0.2 \mathrm{~V}$ to $+1.35 \mathrm{~V}\left(\mathrm{E}_{\text {step }}=15 \mathrm{mV}, \mathrm{E}_{\text {amplitude }}=40 \mathrm{mV}\right.$, frequency $\left.=200 \mathrm{~Hz}\right)$.

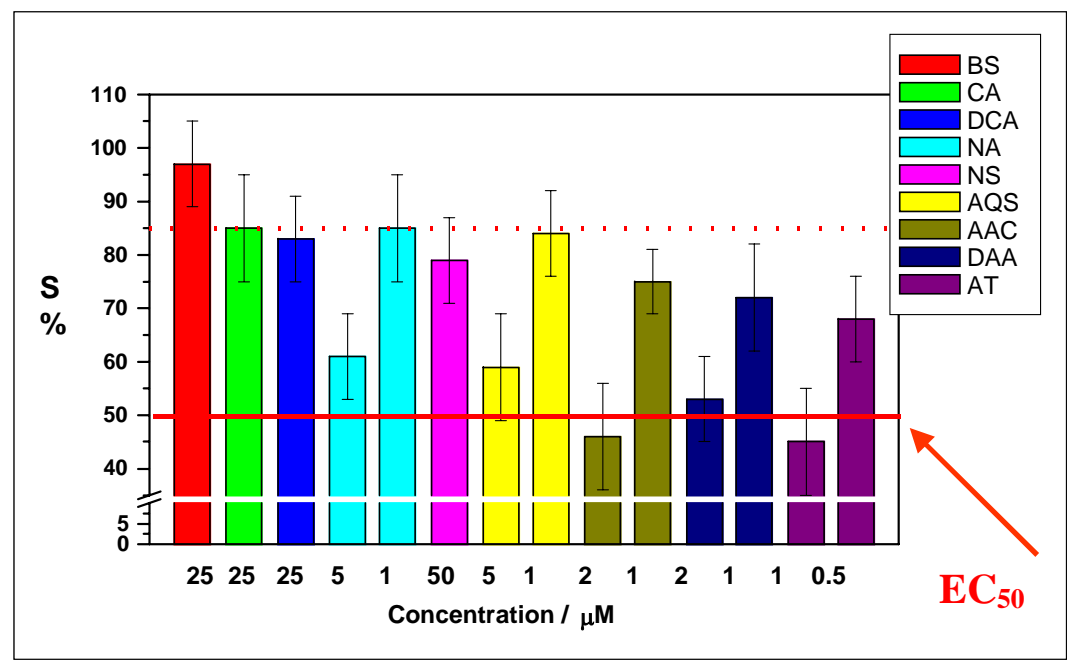

Figure 3. Bioassays for different ecotoxic compounds. EC $_{50}$ value: ecotoxic concentration required for a $50 \%$ decrease of biosensor signal. Experimental conditions as in Figure 2. 
Table 1. DNA biosensor results for benzene, naphthalene and anthracene derivatives standard solutions present in ACNA area. Experimental conditions as in Figure 2.

\begin{tabular}{|c|c|c|c|}
\hline Compound & $\begin{array}{c}\text { Concentration } \\
(\mu \mathrm{mol} / \mathrm{L})\end{array}$ & $S$ guanine \% & Std. dev. $(N=4)$ \\
\hline \multirow[t]{3}{*}{ sodium benzenesulfonate (BS) } & 100 & 75 & 6 \\
\hline & 50 & 91 & 8 \\
\hline & 25 & 96 & 6 \\
\hline \multirow[t]{3}{*}{ 4-chloroaniline (CA) } & 100 & 78 & 8 \\
\hline & 50 & 92 & 6 \\
\hline & 25 & 85 & 10 \\
\hline \multirow[t]{4}{*}{ 3,4-dichloroaniline (DCA) } & 100 & 43 & 8 \\
\hline & 50 & 75 & 8 \\
\hline & 25 & 84 & 6 \\
\hline & 10 & 97 & 7 \\
\hline \multirow[t]{3}{*}{ 2-naphtylamine (NA) } & 50 & 54 & 7 \\
\hline & 5 & 61 & 9 \\
\hline & 1 & 85 & 12 \\
\hline \multirow[t]{3}{*}{ sodium 2-naphtalenesulfonate (NS) } & 150 & 47 & 8 \\
\hline & 100 & 58 & 9 \\
\hline & 50 & 79 & 6 \\
\hline sodium anthraquinone 2-sulfonate & 25 & 34 & 12 \\
\hline \multirow[t]{3}{*}{ monohydrate (AQS) } & 10 & 51 & 7 \\
\hline & 5 & 55 & 9 \\
\hline & 1 & 90 & 6 \\
\hline \multirow[t]{3}{*}{ 2-anthracencarboxylic acid (AAC) } & 5 & 42 & 10 \\
\hline & 2 & 61 & 7 \\
\hline & 1 & 71 & 5 \\
\hline \multirow[t]{3}{*}{ 1,2-diamineanthraquinone (DAA) } & 5 & 59 & 10 \\
\hline & 2 & 65 & 10 \\
\hline & 1 & 79 & 6 \\
\hline \multirow[t]{3}{*}{ 2-anthramine (AT) } & 2.0 & 33 & 10 \\
\hline & 1.0 & 47 & 6 \\
\hline & 0.5 & 73 & 8 \\
\hline
\end{tabular}

\subsection{Optimisation of the extraction procedure}

In order to optimise an extraction procedure (optimisation of the time, solvent and $\mathrm{pH}$ of extraction), some reference soil was artificially polluted with an addition of a known amount of 2-anthramine or 2- 
anthracen carboxylic acid, then an extraction was carried out and the extracts were analysed with the biosensor and UV-VIS spectroscopy. The choice of these two compounds was based on their different chemical nature and being the strongest compounds that gave interaction with the biosensor.

The traditional extraction method for solid matrices is Soxhlet. This method is time-and labour intensive (24-48 h) and require large amounts of organic solvents. Another technique is the ultrasound extraction, that has faster extraction times than Soxhlet, is a relatively low-cost method and uses small volumes of solvent [13]. Recently, new extraction methods have been developed, e.g. microwave assisted extraction with an organic solvent (MAE) or with water (WME) [14], supercritical fluid extraction (SFE) [15], fluidized bed extraction (FBE) [4] and pressurised liquid extraction (PLE) [16]. Several studies have shown that these methods can be equally or even more efficient than Soxhlet extraction [4, 14], although, in some cases they have been reported to be less efficient [14]. Thus, it appears that the extraction efficiencies of these new methods are more dependent on analyte properties, sample quality and optimisation than Soxhlet extraction $[13,16]$.

Anyway, in our case a cheap, fast and easy procedure was needed and was based on ultrasonic extraction $[13,17]$ with a short time (2 min) and few amount of solvent $(10 \mathrm{~mL})$.

For the extraction of 2-anthramine (AT) a proper amount of reference soil was spiked with AT in order to have $20 \mu \mathrm{M}$ AT with $100 \%$ recovery. An ultrasound bath and two different types of extracting solvents with an alcoholic nature, in order to avoid the extraction of AT, were used (a mixture of EtOH - $25 \mathrm{mM}$ phosphate buffer (PBS) containing $25 \mathrm{mM} \mathrm{NaCl}$ (pH 9.0) (30:70) and EtOH alone). The results demonstrated that an extraction time higher than $60 \mathrm{~min}$ is necessary to be able to have at least a recovery of $45 \%$ (which was estimated through UV spectroscopy) and it was observed that the extraction of AT was better at an alkaline pH (Table 2). The AT has an amino group in its molecule, therefore a neutral or slightly alkaline $\mathrm{pH}$ would help its solubilisation in the solvent. Anyway, $60 \mathrm{~min}$ of extraction was a long period for a methodology being considered for use in the field. Hence, in the following phase of optimisation the time of extraction was diminished using an ultrasound probe with a greater power. With the probe three types of extracting solvents were used $\left(\mathrm{EtOH} / \mathrm{H}_{2} \mathrm{O}(90: 10) ; 50\right.$ $\mathrm{mM}$ PBS (pH 7.5) and $50 \mathrm{mM}$ PBS (pH 3.0)) and different times of extractions were carried out (1, 2, 5 and $10 \mathrm{~min}$ ). The results demonstrated that times longer than 5 min generated very stable suspensions due to the intense crushing of particles of the ground that made the ulterior phase of filtration more difficult; therefore these times were not chosen for the following experiments. The extractions with 1 and 2 min produced low percentages of recovery (the best one was 34\%), but these kind of extractions were for screening in the field and this could justify the low level of recovery with these short times (Table 3). Also in this case it was observed that the extraction of AT was better at an alkaline $\mathrm{pH}$.

For the extraction of 2-anthracenecarboxylic acid (AAC), a proper amount of reference soil was spiked with AAC in order to have $20 \mu \mathrm{M}$ AAC with $100 \%$ recovery. Different extraction times with ultrasound probe (1 and $2 \mathrm{~min}$ ) and different extracting solvents (ethanol - water (90:10); $50 \mathrm{mM}$ phosphate buffer $\mathrm{pH} 7.5$ and 3.0) were tried. The results demonstrated that the extraction of this compound was less influenced by the $\mathrm{pH}$ of the extracting solvent (Table 4). The best \% of recovery 
was obtained with a solvent composed of phosphate with salvage values of 96 and $88 \%$. The extract obtained with ethanol had a low level of recovery (37\%) and it was not chosen for the extraction of real soil samples.

Table 2. \% recovery of the extraction of AT with ultrasounds bath with different solvents and times calculated trough UV spectroscopy.

\begin{tabular}{|c|c|c|c|}
\hline Extracting & $\begin{array}{c}\text { \% Recovery } \\
10 \mathrm{~min} \\
\end{array}$ & $\begin{array}{c}\% \text { Recovery } \\
30 \mathrm{~min}\end{array}$ & $\begin{array}{c}\% \text { Recovery } \\
60 \mathrm{~min} \\
\end{array}$ \\
\hline EtOH / 25mM PBS + 25mM NaCl pH 9.0 (30:70) & 0 & 15 & 45 \\
\hline EtOH & n.p. & n.p. & 32 \\
\hline
\end{tabular}

n.p. not performed.

Table 3. \% recovery of the extraction of AT with ultrasounds probe with different solvents and times calculated trough UV spectroscopy.

\begin{tabular}{c|cc}
\hline Extracting & $\begin{array}{c}\text { \% Recovery } \\
\text { 1 min }\end{array}$ & $\begin{array}{c}\text { \% Recovery } \\
\text { 2 min }\end{array}$ \\
\hline EtOH / $\mathrm{H}_{2} \mathrm{O}(90: 10)$ & 19 & 30 \\
$50 \mathrm{mM}$ PBS pH 7.5 & 22 & 34 \\
$50 \mathrm{mM}$ PBS pH 3.0 & 6 & 7 \\
\hline
\end{tabular}

Table 4. \% recovery of the extraction of AAC with ultrasounds probe with different solvents and times calculated trough UV spectroscopy.

\begin{tabular}{c|cc}
\hline Extracting & $\begin{array}{c}\text { \% Recovery } \\
1 \text { min }\end{array}$ & $\begin{array}{c}\text { \% Recovery } \\
\text { 2 min }\end{array}$ \\
\hline EtOH / $\mathrm{H}_{2} \mathrm{O}(90: 10)$ & 35 & 37 \\
$50 \mathrm{mM}$ PBS pH 7.5 & 76 & 96 \\
50mM PBS pH 3.0 & 71 & 88 \\
\hline
\end{tabular}

\subsection{Analysis of real soil samples with DNA biosensor}

In ACNA site the environmental risk arises from pollution diffused in the ground, accumulation of waste materials and pollution of the Bormida river. Four zones in a specific ACNA's area (hill $n^{\circ} 5$ ) were sampled in March 2003: zone 1 low contamination level; zone 2 pseudo-reference; zone 3 moderate pollution level and zone 4 high ecological risk.

Subsequently, the hill was destroyed and another sampling at the basement was made in January 2004. A polluted soil sample of this last sampling was mixed with a control soil (1:5 and 1:10) and the 
extraction was performed with milli-Q water (1:3 v/v) by the Department of Environmental and Life Sciences (DISAV), University of Eastern Piedmont, Alessandria, Italy.

ACNA samples were analysed with DNA biosensor and the different zones and dilutions were compared.

The comparison of the zones with the superficial sampling (max $5 \mathrm{~cm}$ depth) didn't showed a significant difference between them (Figure 4). The comparison of the zones with $20 \mathrm{~cm}$ sampling depth showed differences between them, showing a trend of pollution as expected (Figure 5): the biosensor was able to distinguish different soil contamination sites. The comparison between the different depths and extraction pHs of the zone 4 showed a contamination increasing with the sampling depth and small differences between pHs (Figure 6). The results confirmed the fact that this zone is the most polluted of the hill $n^{\circ} 5$.

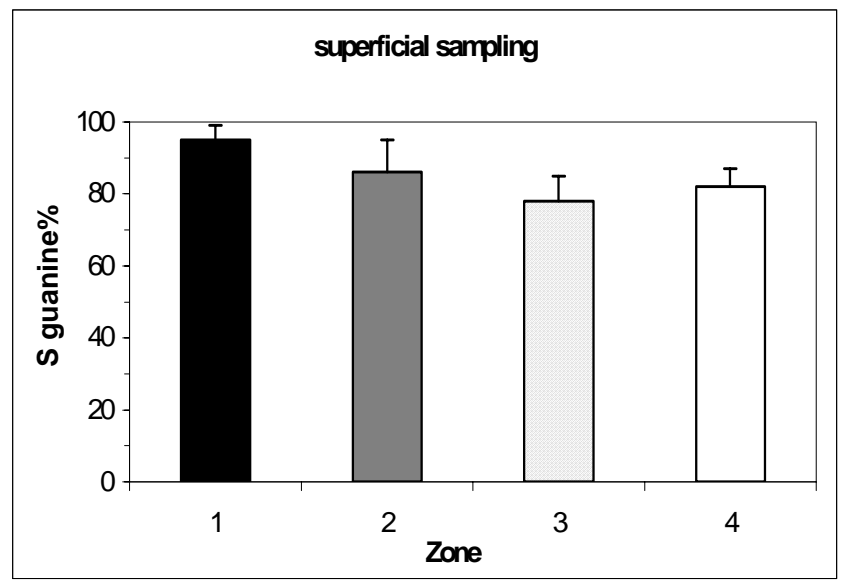

Figure 4. DNA biosensor results for superficial sampling in the four zones of hill $n^{\circ} 5$ in ACNA area (sampling of 2003). Extraction with 50 mM PBS pH 7.5, ultrasound probe 2 min. Electrochemical experimental conditions as in Figure 2.

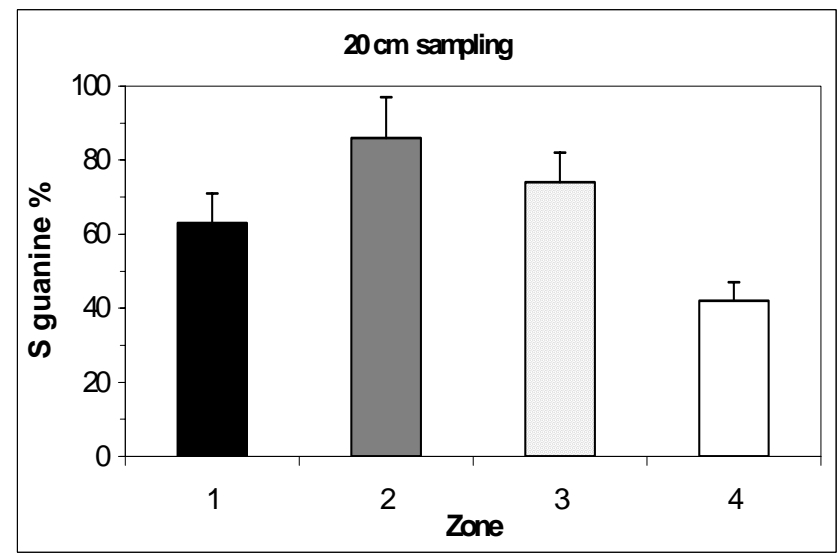

Figure 5. DNA biosensor results for $20 \mathrm{~cm}$ sampling in the four zones of hill $\mathrm{n}^{\circ} 5$ in ACNA area (sampling of 2003). Extraction with $50 \mathrm{mM}$ PBS pH 7.5, ultrasound probe 2 min. Electrochemical experimental conditions as in Figure 2. 


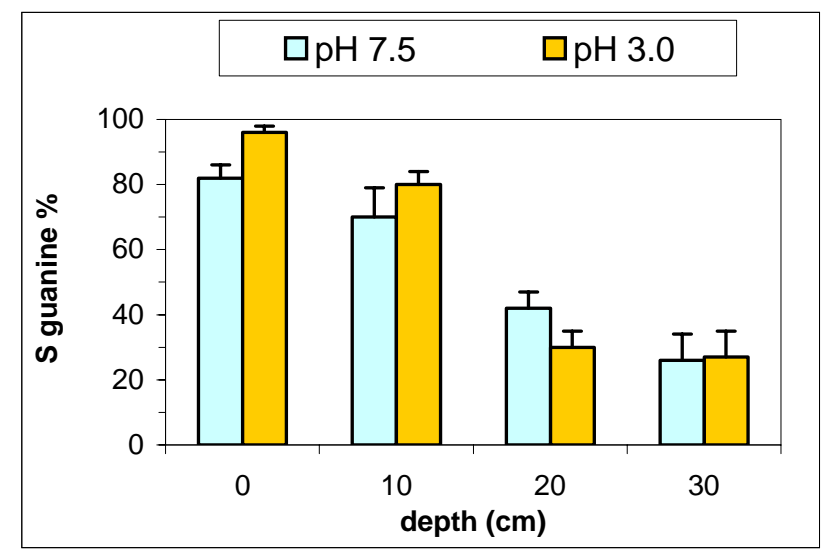

Figure 6. DNA biosensor results for different depths in zone 4 of hill $n^{\circ} 5$ in ACNA area (sampling of 2003). Extraction with 50 mM PBS pH 7.5 or 3.0, ultrasound probe 2 min. Electrochemical experimental conditions as in Figure 2.

ACNA samples were analysed also with micronuclei and Comet tests performed by ISPESL/DIPIA laboratory (Rome, Italy). These are simple and sensitive techniques for analysis and measure of DNA damage in individual mammalian (and to some extent prokaryotic) cells. Seed of Vicia faba var minor were put in ACNA soil samples and the top roots were used for the micronuclei and Comet tests in order to analyse a vegetable mutation after 5 days of exposure. The length of the top roots was also calculated in order to establish a phyto-toxicity. After, half of the roots were prepared for the micronuclei test, the other half for the Comet test. The genotoxic effect was based on the frequency of irregular anaphases and micronucleate cells. The results showed an increase in pollution from zone 1 to 4 and within the zone, with the sampling depth for all methods (Table 5).

Concerning the Comet test, the analyisis showed an increase in DNA damage, corresponding to an increase in pollution, from zone 1 to 4 and with the sampling depth. The results are reported in Table 5 and in Figure 7 which shows an extension of the "comet tail" corresponding to an increase of damage, according to a visual scoring classification from 0 to 4 damage classes.

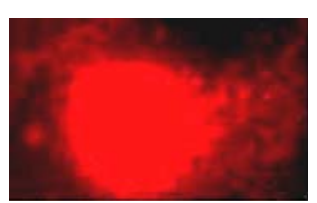

$1 \mathrm{~A}$

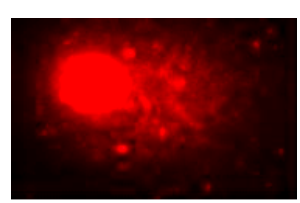

3C

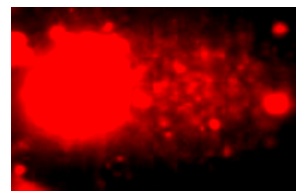

4B

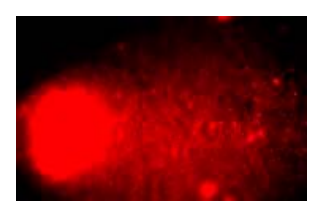

4D

Figure 7. Visual scoring of the Comet test on ACNA soil samples. 
Table 5. Comparison of biosensor results performed on ACNA samples (sampling of 2003) with other bio-assays for toxicity and genotoxicity detection.

\begin{tabular}{c|ccccc}
\hline Sample code & $\begin{array}{c}\text { DNA biosensor } \\
\text { S guanine (\%) }\end{array}$ & $\begin{array}{c}\text { Phyto-toxicity } \\
\text { Primary roots } \\
\text { length (mm) }\end{array}$ & $\begin{array}{c}\text { Genotoxicity } \\
\text { Irregular anaphase } \\
\text { frequency (\%) }\end{array}$ & $\begin{array}{c}\text { Genotoxicity } \\
\text { Micro nucleate } \\
\text { cells frequency (\%) }\end{array}$ & $\begin{array}{c}\text { Comet test } \\
\text { Damage class }\end{array}$ \\
\hline 1A & 99 & 32.7 & 0.05 & 0.18 & 1 \\
1B & 87 & 36.7 & 0.06 & 0.20 & 1 \\
1C & 63 & 18.1 & n.p. & n.p. & n.p. \\
2A & 86 & 35.0 & 0.01 & 0.01 & 1 \\
3A & 78 & 25.9 & 0.01 & 0.03 & 0 \\
3B & 60 & 28.2 & n.p. & n.p. & 0 \\
3C & 74 & 22.8 & n.p. & n.p. & 2 \\
4A & 82 & 21.9 & 0.46 & 0.09 & n.p. \\
4B & 70 & 29.5 & 0.11 & 0.08 & 3 \\
4C & 42 & 14.5 & 0.25 & 0.12 & 1 \\
4D & 26 & 12.7 & 0.52 & 0.64 & 4 \\
\hline
\end{tabular}

A: superficial sampling, B: $10 \mathrm{~cm}, \mathrm{C}: 20 \mathrm{~cm}, \mathrm{D}: 30 \mathrm{~cm}$.

n.p.: not performed.

The analysis with the biosensor on ACNA samples from the 2004 sampling (after the destroy of the hill) showed a stronger genotoxic effect corresponding to a stronger pollution level with the depth in comparison with the superficial sampling of 2003 and a lower genotoxic effect mixing the sample with a control soil (Figure 8). These results were confirmed by the analysis with other bioassays performed by DISAV (Table 6). For example, phytoxicity was calculated by measuring the roots length of allium porrum exposed to the polluted soil (the root is the first plant zone influenced by soil pollutants and its length diminish after a stress); plant genotoxicity was calculated measuring the mitotic anomalies of allium porrum; stress syndrome of earthworms (Lumbricus rubellus) was evaluated by a biomarker battery after 10 days of exposure: lysosomal membrane stability in coelomocytes, $\mathrm{Ca}^{2+}$ ATPase activity on intestinal epithelium, metallothionein content in toto organism, mortality rate.

Interestingly, the results obtained analysing the ACNA soil samples with DNA biosensor were confirmed by other bioassays, hence this kind of biosensor can be very useful as a rapid screening method of analysis. 


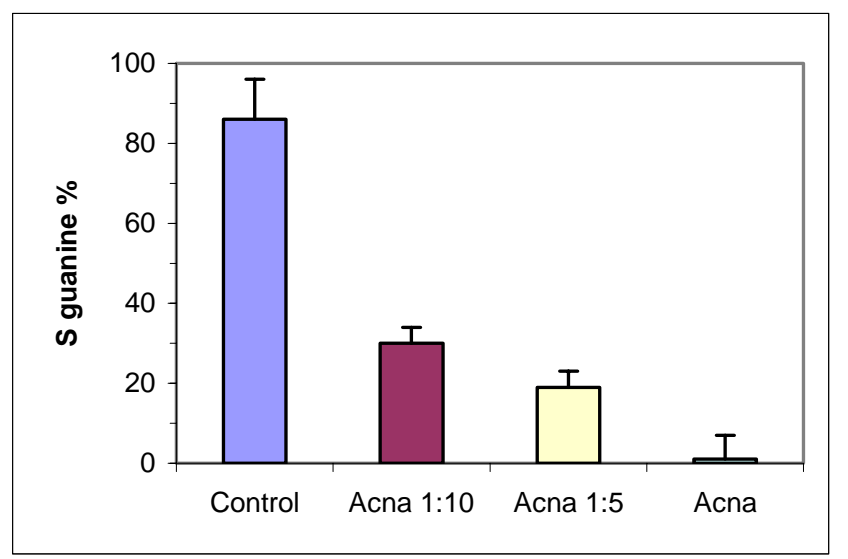

Figure 8. DNA biosensor results for different mixture of a soil from hill $n^{\circ} 5$ in ACNA area with a control soil (sampling of 2004). Extraction with milli-Q water performed by DISAV. Electrochemical experimental conditions as in Figure 2.

Table 6. Comparison of biosensor results performed on ACNA samples (2004 sampling) with other bio-assays for toxicity and stress syndrome detection (results presented at “ $3^{\circ}$ Residential National School of Contaminated Sites”, Alessandria (Italy, $20^{\text {th }}-22^{\text {nd }}$ December 2004)).

\begin{tabular}{l|cccc}
\hline Method \sample code & Control & $1: 10$ & $1: 5$ & ACNA \\
\hline DNA biosensor (S guanine \%) & 86 & 30 & 19 & 1 \\
Roots length of allium porrum (cm) & 2.0 & 1.5 & 0.7 & 0.5 \\
Mitotic anomalies of allium porrum (\%) & 0.10 & 0.20 & n.p & 0.20 \\
Mortality rate of lumbricus rubellus (\%) & 0 & 10 & 25 & 100 \\
Lysosomal membrane stability (optical density \%) & 100 & 28 & 20 & n.p. \\
Ca $^{2+}$-ATPase activity (densitometric value \%) & 100 & 28 & 8 & n.p. \\
Metallothionein content (ng/g) & 150000 & 190000 & 210000 & n.p \\
\hline
\end{tabular}

n.p.: not performed.

3.4. Optimisation of extraction/emission fixed wavelength fluorescence (FF) for 2-anthramine detection

Fixed wavelength fluorescence (FF) was used for the analysis of 2-anthramine standard solutions and some ACNA samples were analysed with this methodology obtaining promising comparative results.

Molecules with aromatic rings with levels at low energy for transition $\pi / \pi^{*}$ are fluorescent, therefore the optimisation of the best wavelength pairs for AT was performed in order to compare DNA biosensor results with a standard methodology.

The optimal wavelength pair, regarding sensitivity was obtained by analysis of $0.5 \mu \mathrm{M}$ AT standard solution prepared in $50 \mathrm{mM}$ phosphate buffer $\mathrm{pH} 7.5$ and 3.0. Emission scans were recorded for fixed 
excitation wavelength ranging from 350 to $380 \mathrm{~nm}$. The optimal emission wavelength was identified at $510 \mathrm{~nm}$ (Figure 9(b)), the sensitivity is excitation dependent. Excitation scans were thereafter recorded with the emission wavelength fixed at $510 \mathrm{~nm}$, showing three highest fluorescence signals (Figure 9(a)). Excitation at $350 \mathrm{~nm}$ resulted the best wavelength for the sensitivity, therefore the best wavelength pairs for AT analysis were $350 / 510 \mathrm{~nm}$. No differences were found between the two pHs (data not shown). The calibration curve, performed with the wavelength pairs of 350/510 nm had a $\mathrm{r}^{2}=$ 0.998 with the AT concentration range of $0.0-1.0 \mu \mathrm{M}$.

Soil samples from zone 4 of hill $n^{\circ 5}$ (sampling of 2003) were analysed with FF as AT-like compounds. A comparison of FF and biosensor results is shown in Figure 10. The soil contamination increased with the sampling depth for both methods, showing that DNA biosensor for qualitative analysis of soil presented a good correlation with a semi-quantitative method for aromatic ring systems determination.

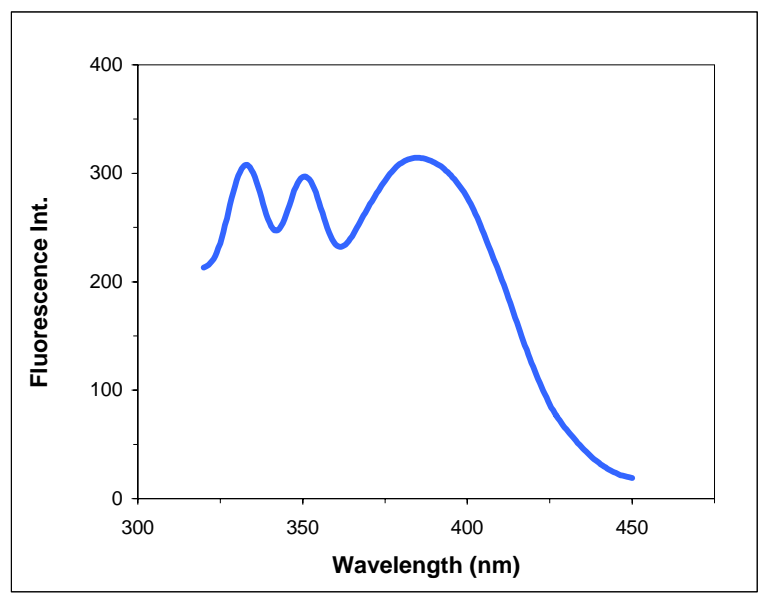

(a)

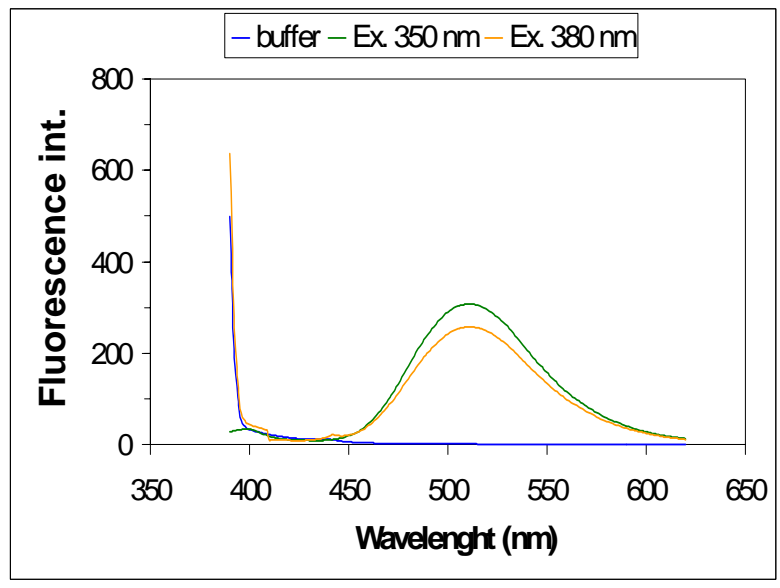

(b)

\section{Conclusions}

Interestingly, agreement in terms of the amount of pollution indicated were found between biosensor results and other methodologies. Therefore this kind of biosensor may represent an easy and fast way of analysis of polluted areas, especially for in-field experiments. A total time of 11 min is necessary to perform the measurement of a sample, after the short extraction procedure. Such DNA biosensors could be useful as early warning devices in areas subject to ecological risk. 
Figure 9. Excitation (a) and emission (b) spectra of $0.5 \mu \mathrm{M}$ AT performed in $50 \mathrm{mM}$ PBS pH 3.0.

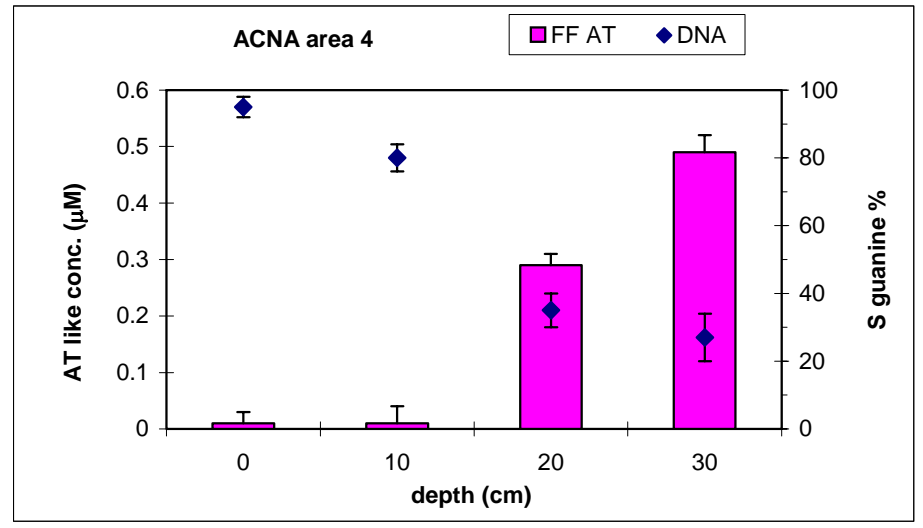

Figure 10. DNA biosensor and $\mathrm{FF}_{350 / 510}$ results for different depths in zone 4 of hill $\mathrm{n}^{\circ} 5$ in ACNA area (sampling of 2003). The samples were extracted with 50 mM PBS pH 3.0. Electrochemical experimental conditions as in Figure 2.

\section{Acknowledgements}

Dr. Graziana Bagni is grateful to Prof. Aldo Viarengo and DISAV for financial support and for the sampling survey organising.

\section{References and Notes}

1. Langdon, C.J.; Piearce, T.G.; Meharg, A.A.; Semple, K.T. Interactions between earthworms and arsenic in the soil environment: a review. Environ. Poll. 2003, 24, 361-373.

2. Ruby, M.V.; Davis, A.; Schoof, R.; Eberle, S.; Sellstore, C.M. Estimation of lead and arsenic bioavailability using a physiologically based extraction test. Environ. Sci. Technol. 1996, 30, 422-430.

3. Berset, J.D.; Ejem, M.; Holzer, R.; Lisher, P. Comparison of different drying, extraction and detection techniques for the determination of priority polycyclic aromatic hydrocarbons in background contaminated soil samples. Anal. Chim. Acta 1999, 383, 263-275.

4. Gfrerer, G.; Serschen, M.; Lankmayr, E. Optimised extraction of polycyclic aromatic hydrocarbons from contaminated soil samples. J. Biochem. Biophys. Methods 2002, 53, 203-216.

5. Chiti, G.; Marrazza, G.; Mascini, M. Electrochemical DNA biosensor for environmental monitoring. Anal. Chim. Acta 2001, 427, 155-164.

6. Lucarelli, F.; Palchetti, I.; Marrazza, G.; Mascini, M. Electrochemical DNA biosensor as a screening tool for the detection of toxicants in water and wastewater samples. Talanta 2002, 56, 949-957. 
7. Lucarelli, F.; Authier, L.; Bagni, G.; Marrazza, G.; Baussant, T.; Aas, E.; Mascini, M. DNA biosensor investigations in fish bile for use as a biomonitoring tool. Anal. Lett. 2003, 9, 1887-1901.

8. Esposito, A; Del Borghi, A.; Vegliò, F. Investigation of naphthalene sulphonate compounds sorption in a soil artificially contaminated using batch and column assays. Waste Manag. 2002, 22, 937-943.

9. Conte, P.; Agretto, A.; Spaccini, R.; Piccolo, A. Soil remediation: humic acids as natural surfactants in the washing of highly contaminated soils. Environ. Poll. 2005, 135, 512-522.

10. Avidano, L.; Gamalero, E.; Cossa, G.P.; Carraro, E. Characterisation of soil health in an Italian polluted site by using microorganisms as bioindicators. Appl. Soil Ecol. 2005, in press.

11. Snyder, R.D.; Arnone, M.R. Putative identification of functional interactions between DNA intercalating agents and topoisomerase II using the V79 in vitro micronucleus assay. Mutat. Res. 2002, 503, 21-35.

12. Lueke, A.; Juhl-Strauss, U.; Krieger, G.; Witte, I. Synergistic DNA damage by oxidative stress (induced by $\mathrm{H}_{2} \mathrm{O}_{2}$ ) and nongenotoxic environmental chemicals in human fibroblasts Toxicol. Lett. 2004, 147, 35-43.

13. Guerin, T.F. The extraction of aged polycyclic aromatic hydrocarbons (PAH) residues from a clay soil using sonication and Soxhlet procedure: a comparative study. J. Environ. Monit. 1999, 1, 63-67.

14. Kramer, B.K.; Ryan, P.B. Soxhlet and microwave extraction in determining the bioaccessibility of pesticides from soil and model solids. Proc. 2000 Conf. Hazard. Waste Res. (Denver, Colorado, USA) 2000, 196-210.

15. Hawthorne, S.B.; Grabanski, C.B.; Martin, E.; Miller, D.J. Comparison of Soxhlet extraction, pressurised liquid extraction, supercritical fluid extraction and subcritical water extraction for environmental solids: recovery, selectivity and effects on sample matrix. J. Chromatogr. A 2000, 892, 421-433.

16. Lundsted, S.; van Bavel, B.; Haglund, P.; Tysklind, M.; Oberg, L. Pressurised liquid extraction of polycyclic aromatic hydrocarbons from contaminated soils J. Chromatogr. A 2000, 883, 151-162.

17. Song, Y.F.; Jing, X.; Fleishmann, S.; Wilke, B.M. Comparative study of extraction methods for the determination of PAHs from contaminated soil and sediments. Chemosphere 2002, 48, 993-1001.

(C) 2005 by MDPI (http://www.mdpi.org). Reproduction is permitted for noncommercial purposes. 